\title{
Are Sexual Double Standards Related to the Proportion of the Opposite Sex in the Environment?
}

\author{
Yue Yin* \\ Faculty of Engineering, China University Of Geosciences, Wuhan, Hubei 430074, China \\ *Corresponding author. Email: qyfyyinyue@163.com
}

\begin{abstract}
Are sexual double standards related to the proportion of men and women in their growing or living environment? Is a balanced sex ratio helpful for teenagers to better get along with their peers? To figure out the answers, I designed an experiment and completed it. The correlation between SDS and sex ratios in environments has not been focused on or found in the former researches. The experiment was assumed to go through a survey of about 100 subjects over 18 years old from different areas by questionnaire. For the same behavior of two genders with different information, participants were supposed to express their attitudes towards the behavior of the person described in the question. After the results of the questionnaire had been collected, I worked out the corresponding statistics by SPSS and integrated the evaluation to get the possible results through 7 analyzing tables and a scatter plot, which proved that SDS is indicated more likely to be correlated to the sex ratios in network environments of the respondents than the living environments. Besides, factors such as competitive pressure of sexual attraction and stereotypes were unexpectedly found as the possible reasons causing SDS in the analyzing. Relevant departments are suggested to take the results as the basis to improve the environment that indirectly leads the social problems, such as coordinating sex ratio and enhancing sexual equality education.
\end{abstract}

Keywords: Sex double standards, environment, sex ratio, stereotype, competitive pressure

\section{INTRODUCTION}

The purpose of this paper is to find out whether the sexual double standards are related to the sex ratios in the long-term living environments of the respondents through research analysis of the results about 100 samples.

In the past, many scholars have studied the sexual double standards, but there are few studies on the correlation between the environment of the sample and the sample itself.

The phenomena of double standards of sex are commonly seen among all generations, which leads to many distortions of the concepts and problems in dealing with interpersonal relationship, such as bickering and contradictions caused by holding double standards for different genders. I focus on the youth in this research. It is helpful for the improvement of social harmony to pay attention to these problems and improve the phenomenon of sexual double standards caused by the imbalance of sex ratio in the environment. Based on the results of this study, we can improve the environment by using some methods, such as balancing the sex ratio as much as possible, strengthening the education of the concept of sexual equality.

\section{PRESENT WORK}

The belief that women and men are held to different standards of sexual conduct is pervasive in contemporary American society [1]. It is also common to hold this kind of views in China.

We often talk about people who have obvious double standards. For example, some women are sometimes too strict with men's material conditions, or some men have a lot of subjective color in judging women in China. Besides, the traditional stereotype in China has probably influenced SDS (sexual double standards) much. However, people in different living environments give different opinions, thus SDS is related to the proportion of the sex ratios in the environments.

I suppose that finding out the influence of different sex ratios in the environments on SDS is helpful to improve teenagers' cognition and better get along with fellows of both genders. 
For the purpose of experimental investigation, I have made a questionnaire survey conducted among about 100 students from different areas in China.

1. The criteria on the same behavior of men or women with different information were divided into 7 grades from 1 to 7 in Likert scale. The personality traits were modeled after the personality characteristics used by McKinney et al. (1987) [2].

2. The subjects made subjective judgments on the morality and ability of men and women of the same type, with similar backgrounds, and judged which one were more likely to be scored higher or lower in the scale.

Age range: $18-34$

\section{EXPERIMENT}

\subsection{Method}

\subsubsection{Participants.}

95 adults participated in the research from different areas, ranging in age from 18 to 34 .

\subsubsection{Procedures.}

This paper investigated the subjects in the form of questionnaire and studied some questions.The questionnaire was an online one from the website:https://www.wjx.cn/

Participants were told that they were participating in a psychological research and able to choose to continue or withdraw according to their own wishes. At the same time, I promised that their personal information would be only used for researching. At the end of the questionnaire, participants could draw some prizes set up in WJX.

The questions asked the respondents to evaluate the same behavior of men or women with different backgrounds. The criteria are divided into 7 grades from 1 to 7 due to the self-rate of the personality characteristics used by McKinney et al. (1987) [2]. Also, participants were asked about the proportion of men and women in their living environments and internet environments, also some other factors such as stereotyping, which were also measured by the same scale.

The results of both genders were then analyzed and evaluated mainly by SPSS.

There were 40 questions to measure the participants in total, and most of them were like these:

"If you see a small animal saved by a man (or a woman) in a dangerous situation. The information about the number of sexual partners and personal interests of the people in the photos are given with the question.
Do you think he or she is a moral person?, ( Range 17, 1 for extreme disapproval, 7 for extreme approval).

An adult man (or a woman) meets ethical standards for having multiple sexual partners at one time., (Range 1-7, 1 for extreme disapproval, 7 for extreme approval)."

In these contrastive questions, for pairs of items approving of sexually active individuals, I was intended to subtract female-biased items from male-biased items; these difference scores reflect discrepancies in respondents' standards for women and men [3].

At the same time, there were also some other questions like:

"women should do housework and watch their children while working, while men only need work.(In this example, the gender workload is roughly the same as compensation)

Please choose from 1 7 to express your attitude towards this opinion."

These questions were supposed to measure the level of SDS of the respondents. When measuring, I summed the scores of these questions up. The total scores of these questions were added to the result of the discrepant ones, and the final total result reflected the level of SDS of the respondents.

Also, some questions were set to measure other variables that might cause SDS such as the level of SDS in their families (listed in the part of Measure). At the end of the questionnaire, they were asked about the approximate ratio of men to women in their classes or majors and in the online environment, which were two variables in the analysis.

Then I compared the scores obtained from the judgment of participants of different genders, and had the data analyzed. Their SDS levels and other results were evaluated by SPSS with the data provided by the results of the questionnaire survey.

\subsubsection{Measure}

In the questionnaire, most of the questions were like these:

Do you think he or she is a moral person?, ( Range 1-7, 1 for extreme disapproval, 7 for extreme approval).

Do you agree with the opinion that men are not obliged to do any housework but women are?, (Range 17, 1 for extreme disapproval, 7 for extreme approval)

In addition, participants were asked to describe the general sex ratios in their living environments. The living environment here could be the college or class they are in. Along with it, the sex ratios in network environments of the participants' were also required to be filled in the questionnaire. Meanwhile, there were also some 
questions designed to measure the SDS in their families.

Generally, there are 8 variables in this research:

(1) Level of SDS; (2) knowledge about sex; (3) SDS in their families; (4) Gender; (5) sex ratio in the living environment; (6) sex ratio in network environment; (7) level of stereotyping; (8) sexual competitive pressure.

(1) is set as a dependent variable, and (2) to (8) are set as independent variables. After getting the result of the questionnaire, the data of the 8 variables are analyzed in SPSS.

\subsubsection{Data Analytic Approach.}

There are 7 independent variables and a dependent variable, which were all measured in the questionnaire by about 40 questions. Each independent variable was measured by the total scores participants got from some correlated questions. And the dependent variable was measured by two parts of questions, the individual ones that focused on males and discrepant ones about SDS. The individual questions were supposed to measure the level of traditional SDS of the respondents. When measuring, I summed the scores of these individual questions up. The total scores of these questions were added to the result of the discrepant ones, and the final total result reflected the level of SDS of the respondents: the higher the final score is, the higher his or her SDS level is.

After confirming the reliability and validity of the data, analysis of correlation and analysis of regression were used to figure out the interrelation of the 8 variables mentioned in Measure. To make the final result more accurate, the 95 results of the questions were divided into two parts of male and female respondents. The correlations of SDS of the participants and the other 7 variables were analyzed by SPSS, which resulted in 19 ( 1 for gender and 18 for the other six variables) forms for analysis of correlations. According to the results, some of them were correlated obviously at the 0.01 level or the 0.05 level, thus they are listed in the Results of this paper.

\section{HYPOTHESIS}

I supposed that the imbalance of sex ratio might lead

Table 1. Descriptive statistics of the 8 variables: level of SDS, knowledge about sex, SDS in their families, gender, sex ratio in the living environment, sex ratio in network environment, level of stereotyping, competitive pressure of sexual attraction

Descriptive Statistics

\begin{tabular}{cccccc}
\hline & $N$ & Minimum & Maximum & Mean & Std. Deviation \\
\hline level of SDS & 95 & -62.30 & -9.60 & -33.3926 & 8.66096 \\
knowledge about sex & 95 & 2.00 & 14.00 & 9.1158 & 2.87640 \\
SDS in their families & 95 & -1.00 & 1.00 & 0.3789 & 0.78793 \\
gender & 95 & -1.00 & 1.00 & -0.3053 & 0.95732
\end{tabular}

to the phenomenon of SDS indirectly. The environment with large proportions of males might lead to stricter standards for females to judge the morality and ability of the males than the environment with a nearly balanced sex ratio. Oppositely, the environment with large proportion of females may lead to stricter standards for males to judge the morality and ability of females than the environment with a nearly sex ratio.

The assumption above may result from the fact that different competitive pressure of sexual attraction in the long-term living environment, or the lack of contact with the opposite sex and knowledge about the opposite sex. For implicit sexual standards, men demonstrated a relatively gender-neutral evaluation and women demonstrated a strong reverse double standard [4].

Furthermore, I have the following two conjectures about the possible results:

If the results show that men (women) have stricter criteria for females (males) than themselves, while women (men) have lower criteria for males (females) than females (males), and the proportion of females (males) in the environment is larger than which of men (women), then this result may be caused by competitive sexual attraction pressure.

If the results show that women (men) have stricter criteria for males (females) than themselves, while men (women) have lower one for females (males) than themselves in a balanced sex ratio environment. It may be due to the lack of contact with the opposite gender and knowledge about the opposite sex. Males (females) in this environment probably judge females (males) by the standards of their own, which may lead to some deviations, also be one of the reasons causing SDS. For example, it is not fair for girls to be requested as fast as boys in a usual class when they are running. In this case, criteria for the females are ought to be lower than which for males.

\section{RESULTS}

There are totally 95 answer sheets from the questionnaire, which are proved to be all valid and reliable. 


\begin{tabular}{cccccc}
$\begin{array}{c}\text { sex ratio in the living } \\
\text { environment }\end{array}$ & 95 & 0.09 & 0.99 & 0.4789 & 0.24134 \\
sex ratio in network environment & 95 & 0.00 & 1.00 & 0.4401 & 0.21749 \\
level of stereotyping & 95 & 3.00 & 17.00 & 4.6632 & 2.73516 \\
competitive pressure of sexual & 95 & 1.00 & 7.00 & 1.4842 & 1.05046 \\
attraction & & & & & \\
Valid N (listwise) & 95 & & & & \\
\hline
\end{tabular}

Here are two tables to illustrate its reliability and validity:

Table 2. Reliability and validity

\begin{tabular}{cccc}
\multicolumn{2}{c}{ Reliability and validity } & \\
\hline Reliability Statistics & Cronbach's Alpha & N of Items & \\
& .085 & 8 & 0.519 \\
KMO and Bartlett's Test & Kaiser-Meyer-Olkin Measure of Sampling Adequacy. & 99.321 \\
& & Approx. Chi-Square & 28 \\
& Bartlett's Test of Sphericity & Sig. & 0.000 \\
\hline
\end{tabular}

From the result of SPSS, it proves that SDS level has a lot to do with the level of stereotyping, sex ratio in network environment and the gender of the participants. The two main variables that may cause SDS are stereotyping and gender.

Here list the results of the analysis of correlation in Table 3:

Table 3. Analyzing of correlations (Pearson) of 95 samples of both genders

\section{Correlations}

\begin{tabular}{|c|c|c|c|c|c|c|c|c|c|}
\hline & & Level of SDS & $\begin{array}{c}\text { knowledge } \\
\text { about sex }\end{array}$ & $\begin{array}{l}\text { SDS in } \\
\text { their }\end{array}$ & gender & $\begin{array}{l}\text { sex ratio in } \\
\text { the living } \\
\text { environm }\end{array}$ & $\begin{array}{l}\text { ex ratio in } \\
\text { network } \\
\text { environme }\end{array}$ & $\begin{array}{l}\text { level of } \\
\text { stereotypi }\end{array}$ & $\begin{array}{c}\text { competiti } \\
\text { ve } \\
\text { pressure }\end{array}$ \\
\hline & & & & families & & $\mathrm{nt}$ & nt & ng & of \\
\hline & Pearson & 1 & 152 & : & O $271^{* *}$ & ก 170 & $2320^{*}$ & (2) & 121 \\
\hline Level of & Correlation & 1 & $-0.1 J 2$ & -0.001 & 0.271 & $0.1 / 10$ & $0 . \angle 39$ & .200 & $-0.1<4$ \\
\hline SDS & Sig. (2-tailed) & & 0.143 & 0.518 & 0.008 & 0.100 & 0.020 & 0.005 & 0.233 \\
\hline & $\mathrm{N}$ & 95 & 95 & 95 & 95 & 95 & 95 & 95 & 95 \\
\hline & Pearson & 215 & 1 & 173 & * & ก००6 & & * & \\
\hline knowledge & Correlation & -0.152 & 1 & $0.1 / 3$ & 0.225 & -0.096 & -0.035 & -0.224 & -0.198 \\
\hline about sex & Sig. (2-tailed) & 0.143 & & 0.094 & 0.028 & 0.354 & 0.734 & 0.029 & 0.054 \\
\hline & $\mathrm{N}$ & 95 & 95 & 95 & 95 & 95 & 95 & 95 & 95 \\
\hline SDS in & $\begin{array}{c}\text { Pearson } \\
\text { Correlation }\end{array}$ & -0.067 & 0.173 & 1 & -0.127 & $-0.203^{*}$ & -0.055 & -0.009 & 0.033 \\
\hline thelr & Sig. (2-tailed) & 0.518 & 0.094 & & 0.220 & 0.048 & 0.600 & 0.929 & 0.751 \\
\hline & $\mathrm{N}$ & 95 & 95 & 95 & 95 & 95 & 95 & 95 & 95 \\
\hline & $\begin{array}{c}\text { Pearson } \\
\text { Correlation }\end{array}$ & $0.271^{* *}$ & $0.225^{*}$ & -0.127 & 1 & $0.407^{* *}$ & $0.467^{\star *}$ & -0.072 & 0.022 \\
\hline & Sig. (2-tailed) & 0.008 & 0.028 & 0.220 & & 0.000 & 0.000 & 0.487 & 0.835 \\
\hline & $\mathrm{N}$ & 95 & 95 & 95 & 95 & 95 & 95 & 95 & 95 \\
\hline
\end{tabular}




\begin{tabular}{|c|c|c|c|c|c|c|c|c|c|}
\hline $\begin{array}{l}\text { sex ratio in } \\
\text { the living }\end{array}$ & $\begin{array}{c}\text { Pearson } \\
\text { Correlation }\end{array}$ & 0.170 & -0.096 & $-0.203^{*}$ & $0.407^{* *}$ & 1 & $0.258^{*}$ & 0.040 & 0.102 \\
\hline environme & Sig. (2-tailed) & 0.100 & 0.354 & 0.048 & 0.000 & & 0.012 & 0.704 & 0.324 \\
\hline nt & $\mathrm{N}$ & 95 & 95 & 95 & 95 & 95 & 95 & 95 & 95 \\
\hline $\begin{array}{l}\text { sex ratio in } \\
\text { network }\end{array}$ & $\begin{array}{c}\text { Pearson } \\
\text { Correlation }\end{array}$ & $0.239^{*}$ & -0.035 & -0.055 & $0.467^{* *}$ & $0.258^{*}$ & 1 & 0.042 & 0.068 \\
\hline environme & Sig. (2-tailed) & 0.020 & 0.734 & 0.600 & 0.000 & 0.012 & & 0.684 & 0.512 \\
\hline $\mathrm{nt}$ & $\mathrm{N}$ & 95 & 95 & 95 & 95 & 95 & 95 & 95 & 95 \\
\hline \multirow{3}{*}{$\begin{array}{c}\text { level of } \\
\text { stereotypin } \\
q\end{array}$} & $\begin{array}{c}\text { Pearson } \\
\text { Correlation }\end{array}$ & $0.286^{* *}$ & $-0.224^{*}$ & -0.009 & -0.072 & 0.040 & 0.042 & 1 & $0.254^{*}$ \\
\hline & Sig. (2-tailed) & 0.005 & 0.029 & 0.929 & 0.487 & 0.704 & 0.684 & & 0.013 \\
\hline & N & 95 & 95 & 95 & 95 & 95 & 95 & 95 & 95 \\
\hline \multirow{3}{*}{$\begin{array}{l}\text { competitiv } \\
\text { e pressure } \\
\text { of }\end{array}$} & $\begin{array}{c}\text { Pearson } \\
\text { Correlation }\end{array}$ & -0.124 & -0.198 & 0.033 & 0.022 & 0.102 & 0.068 & $0.254^{*}$ & 1 \\
\hline & Sig. (2-tailed) & 0.233 & 0.054 & 0.751 & 0.835 & 0.324 & 0.512 & 0.013 & \\
\hline & $\mathrm{N}$ & 95 & 95 & 95 & 95 & 95 & 95 & 95 & 95 \\
\hline
\end{tabular}

**. Correlation is significant at the 0.01 level (2-tailed).

*. Correlation is significant at the 0.05 level (2-tailed).

SDS and gender are correlated obviously at the level of 0.01 . SDS and sex ratio in network environment are correlated obviously at the level of 0.05 . When only analyzing the data from 33 male participants, SDS and knowledge about sex are correlated obviously at the level of 0.05 . When the variable comes to the level of stereotyping, it proves that SDS level and stereotyping level are correlated obviously in 0.01 level. Even only compared in a single gender, the result is that they are correlated obviously in 0.05 level (Table 4).

Table 4. Analyzing of correlations (Pearson) of 33 samples of males

\begin{tabular}{cccc}
\multicolumn{2}{c}{ Correlations } & \\
\hline & & Level of SDS & knowledge about sex \\
\hline \multirow{2}{*}{ Level of SDS } & Pearson Correlation & 1 & $-0.417^{*}$ \\
& Sig. (2-tailed) & & 0.016 \\
knowledge about sex & $\mathrm{N}$ & 33 & 33 \\
& Pearson Correlation & $-0.417^{*}$ & 1 \\
& Sig. (2-tailed) & 0.016 & 33 \\
\hline
\end{tabular}

*. Correlation is significant at the 0.05 level (2-tailed).

Meanwhile, it indicates that SDS level and knowledge about sex are not correlated significantly. Thus, the second suppose in the hypothesis is not proved in the result of the correlation analyzing in the condition of analyzing two genders at the same time. But from the analyzing of regression (Table 5 to Table 7), it proves that SDS is additionally effected by competitive pressure of sexual attraction and knowledge about sex. And the former one factor influence the SDS more than the latter one. As the correlation of SDS and sex knowledge is obvious in the 33 male respondents, it is supposed that SDS of male might be caused by insufficient knowledge about sex.

Table 5. Model summary of 95 samples

Model Summary

\begin{tabular}{lllll}
\hline Model & R & R Square Adjusted R Std. Error of & Change Statistics & Durbin-
\end{tabular}




\begin{tabular}{|c|c|c|c|c|c|c|c|c|c|c|}
\hline & & & Square & the Estimate & $\begin{array}{c}\text { R Square } \\
\text { Change }\end{array}$ & $\begin{array}{c}\mathrm{F} \\
\text { Change }\end{array}$ & $d f 1$ & $\mathrm{df} 2$ & $\begin{array}{l}\text { Sig. F } \\
\text { Change }\end{array}$ & Watson \\
\hline 1 & $0.509^{a}$ & 0.259 & 0.200 & 7.74760 & 0.259 & 4.353 & 7 & 87 & 0.000 & 2.142 \\
\hline
\end{tabular}

a. Predictors: (Constant), competitive pressure of sexual attraction, gender, SDS in their families, level of stereotyping, knowledge about sex, sex ratio in the living environment, sex ratio in network environment

b. Dependent Variable: Level of SDS

Table 6. ANOVA of 95 samples

ANOVA $^{a}$

\begin{tabular}{ccccccc}
\hline & Model & Sum of Squares & $\mathrm{df}$ & Mean Square & F & Sig. \\
\hline \multirow{3}{*}{1} & Regression & 1828.940 & 7 & 261.277 & 4.353 & $0.000^{\mathrm{b}}$ \\
& Residual & 5222.204 & 87 & 60.025 & & \\
& Total & 7051.145 & 94 & & & \\
\hline
\end{tabular}

a. Dependent Variable: Level of SDS

b. Predictors: (Constant), competitive pressure of sexual attraction, gender, SDS in their families, level of stereotyping, knowledge about sex, sex ratio in the living environment, sex ratio in network environment

Table 7. Coefficients of 95 samples

\begin{tabular}{|c|c|c|c|c|c|c|c|c|}
\hline \multicolumn{9}{|c|}{ Coefficients $^{a}$} \\
\hline & \multicolumn{8}{|c|}{ Standardized } \\
\hline & \multirow[b]{2}{*}{ Model } & \multicolumn{2}{|c|}{ Unstandardized Coefficients } & \multirow{2}{*}{$\frac{\text { Coefficients }}{\text { Beta }}$} & \multirow[b]{2}{*}{$\mathrm{t}$} & \multirow[b]{2}{*}{ Sig. } & \multicolumn{2}{|c|}{ Collinearity Statistics } \\
\hline & & B & Std. Error & & & & Tolerance & VIF \\
\hline \multirow[t]{8}{*}{1} & (Constant) & -31.065 & 4.862 & & -6.389 & 0.000 & & \\
\hline & $\begin{array}{l}\text { knowledge } \\
\text { about sex }\end{array}$ & -0.587 & 0.310 & -0.195 & -1.894 & 0.062 & 0.803 & 1.246 \\
\hline & $\begin{array}{l}\text { SDS in their } \\
\text { families }\end{array}$ & 0.285 & 1.060 & 0.026 & 0.269 & 0.789 & 0.916 & 1.092 \\
\hline & gender & 2.642 & 1.068 & 0.292 & 2.473 & 0.015 & 0.610 & 1.638 \\
\hline & $\begin{array}{l}\text { sex ratio in the } \\
\text { living } \\
\text { environment }\end{array}$ & 0.965 & 3.756 & 0.027 & 0.257 & 0.798 & 0.777 & 1.287 \\
\hline & $\begin{array}{c}\text { sex ratio in } \\
\text { network } \\
\text { environment }\end{array}$ & 3.751 & 4.229 & 0.094 & 0.887 & 0.377 & 0.755 & 1.325 \\
\hline & $\begin{array}{c}\text { level of } \\
\text { stereotyping }\end{array}$ & 1.030 & 0.308 & 0.325 & 3.347 & 0.001 & 0.901 & 1.110 \\
\hline & $\begin{array}{l}\text { competitive } \\
\text { pressure of } \\
\text { sexual } \\
\text { attraction }\end{array}$ & -2.152 & 0.802 & -0.261 & -2.683 & 0.009 & 0.899 & 1.112 \\
\hline
\end{tabular}

a. Dependent Variable: Level of SDS 


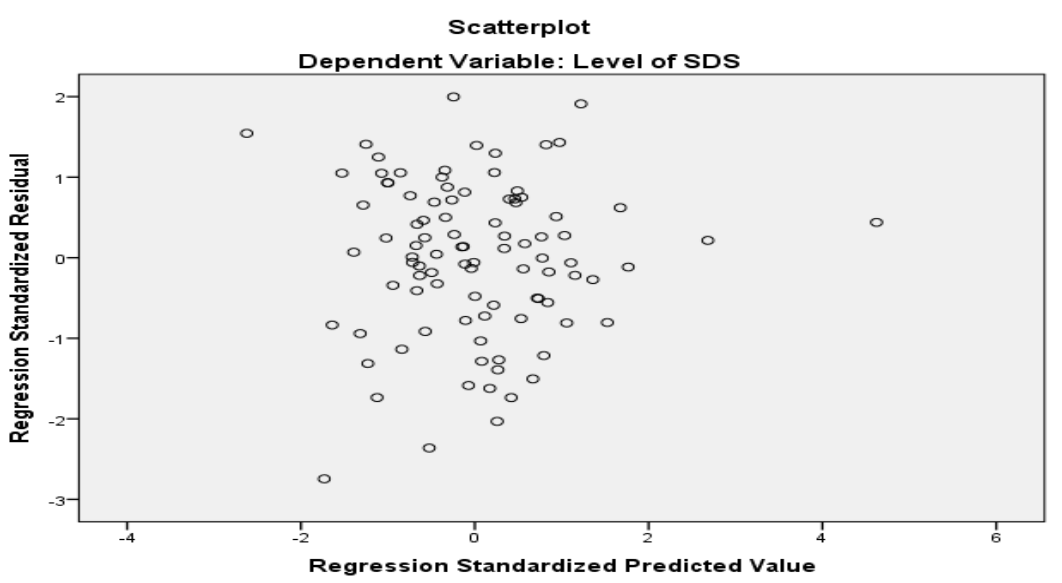

Figure 1. Scatter plot of dependent variable: level of SDS.

The result proves that the sex ratio in reality may not influence one's SDS level outstandingly. However, the sex ratio in network environment has something to do with the SDS level of the participants. As is known, the environment of one's network can be chosen by himself or herself, which may not be the influence factor of SDS level.

Unexpectedly, it is found that competitive pressure of sexual attraction has obvious correlation to the level of SDS in the analysis of regression. The significance in the regression form indicates that there are three factors correlated to SDS obviously: (1) gender; (2) level of stereotyping; (3) competitive pressure of sexual attraction. As studied in the past, different SDS levels are usually associated to gender and stereotype. This means that the first suppose in the hypothesis is more likely to be correct from the data in the result of SPSS.

It is a new finding that sexual competitive pressure has something to do with people's SDS level. This might result from the fact that the more competitive the sexual attraction pressure is, the higher the SDS level is. As is asked in the questionnaire, people who has less SDS level score agree with the opinion that female should be specially treated in the condition of that the number of females is less than males in the environment. It has been proved in the research of other scholars that traditional SDS means that men usually have more authorities and power than women [5]. From the results, it could be supposed that:

When the sex ratio of the environment is not average of the two gender (male and female), the sexual competitive pressure might be more severe, which may lead to the lower standards towards the gender of a smaller number. For example, as is written in the questionnaire, sometimes people are probably more likely to agree that men are ought to earn much more money than their lovers when the sex ratio of females is much less than males. The respondents who agree with this opinion are more likely to have less SDS scoring, which means lower criteria for females and more authorities that they suppose females should have.

In this case, the ratios of sex in the environments people live in are required to be approximately balanced. As a result of excessive sexual competitive pressure, involution might be caused in the groups of people with the major gender, and the others with the minority gender may receive unnecessary admiration or authorities, which is possibly the reason why some males are more frequently exclaiming that they have much more responsibilities and pressures than females in their relationships nowadays.

\section{CONCLUSION}

This research is to figure out the interrelation of SDS and environmental sex ratio. Based on the results of this study, we can improve the environment that leads to social problems, such as balancing the sex ratios as much as possible, enhancing the education of the concept of sexual equality and so on. In the measuring, I integrated the evaluation results of both genders with the proportion of men and women, and got the possible results through the forms.

The results indicate that SDS is related to the different competitive pressure of sexual attraction in the network environment. From the analyzing of correlation, it proves that SDS level has a lot to do with the level of stereotyping, sex ratio in network environment and the gender of the participants. The two main variables that may cause SDS are stereotyping and gender, which are additionally found in this research. From the analyzing of regression, it proves that SDS is additionally effected by competitive pressure of sexual attraction. In this case, a balanced sex ratio in the environment lessens much unnecessary competitive pressure of sexual attraction, which is probably a better environment for teenagers to grow up in.

It is supposed in the hypothesis that the improvement of different sex ratios in the living or growing environments on SDS is helpful to improve teenagers' 
cognition of both genders, forming relatively right values. The research is aimed to promote solving the social double standards problem through the realizable breakthrough, which is easier to operate than improving long-term deep-rooted minds like stereotypes. However, sex education is also needed to teach teenagers how to get along well with the opposite sex and the misunderstandings caused by stereotypes.

In general, SDS is indicated more likely to be correlated to the sex ratios in network environments of the respondents than the living environments. However, network environments are controlled by people themselves, so that it is probably more difficult to improve them by balancing the sex ratios in network for they are due to one's own preference. Fortunately, it is found in this research that the stereotypes and competitive pressure of sexual attraction, which are possible to be improved by adjusting the sex ratios, also influence the SDS. In that case, it is a procurable choice for the relative departments to try to balance the sex ratios in schools or work places.

\section{Limitations:}

The samples in the research might not be so abundant that the results are probably not the closest. People sometimes did not feel free to fill the questionnaire under the condition of being informed that this was a psychological research, so that the answers were more likely to be neutral and of morality, with some scruples in their minds.

People's choice of different environments may result from that a specific gender is sometimes more suitable for doing something, and it may be difficult to achieve a general balance of sex ratio in the work and living environment with unbalanced sex ratio in a short time.

\section{REFERENCES}

[1]. Kreager, D. A., Staff, J. (2009) The Sexual Double standards and Adolescent Peer Acceptance. Social Psychology Quarterly, Vol. 72, No. 2, 143-164.

[2]. Hynie, M., Lydon, J. E. (1995) Women's perception of female contraceptive behavior. Psychology of Women Quarterly, 19, 563-581.

[3]. Caron, S. L., Davis, C. M., Halteman, W. A., Stickle, M., Lottes, I. L., Weinberg, M. S., Muehlenhard, C. L., Quackenbush, D. M. (2011) Double Standard. In: Terri, D. F., Clive, M. D., William, L. Y., Sandra. L. D. (Eds.), Handbook of Sexuality-Related Measures. Routledge., New York. pp. 195-201.

[4]. Sakaluk, J. K., Milhausen, R. R. (2012) Factors Influencing University Students' Explicit and Implicit Sexual Double standards. Journal of Sex Research, 49:5, 464-476.
[5]. Niemi, L., Young, L. (2016) When and Why We See Victims as Responsible: The Impact of Ideology on Attitudes Toward Victims. Personality and Social Psychology Bulletin, Vol. 42(9), 12271242 . 